\title{
Achieving supply chain integration within construction industry
}

Peter McDermott (SCRI Research Centre in the Built and Human Environment (BuHu), University of Salford, Salford, Greater Manchester, UK) and Malik M A Khalfan (SCRI Research Centre in the Built and Human Environment (BuHu), University of Salford, Salford, Greater Manchester, UK)

\section{ABSTRACT}

The main driver behind the adoption of supply chain management (SCM) philosophy into the construction industry was the successes within other industry sectors. SCM can be defined as network of different organisations, linked upstream and downstream in a chain, aiming to produce quality and value in the services and products for the end consumers through integrated processes and activities. In order to achieve the optimised level of integration of the whole supply chain, the industry has responded in various forms. This paper will discuss different initiatives by the researchers, construction industry, and the UK government in order to achieve optimal level of supply chain integration. This paper will discuss the concept of aggregation, and also look at other supply chain integration related concepts including client-led supply chain, knowledge about the whole supply chain, effects of procurement on integration of supply chain, etc. The paper will give a brief overview and initial findings of a project undertaken by the authors, and also include examples from the UK construction industry on bundling of the supply and demand.

Keywords: Supply Chain Management, Supply Chain Integration, Construction Industry.

\section{INTRODUCTION}

Since the middle of the 1990's, the researchers and practitioners within the construction industry have moved towards Supply Chain Management (SCM) philosophy in order to make construction industry more effective and more efficient. The main driver behind the adoption of this philosophy was the successes within other industry sectors. SCM can be defined as network of different organisations, linked upstream and downstream in a chain, aiming to produce quality and value in the services and products for the end consumers through integrated processes and activities. In order to achieve the optimised level of integration of the whole supply chain, the industry has responded in various forms. This paper will give an overview of what is being done in general and specifically within construction industry to support the integration of supply chain. Saad et al. (2002) argue that the construction industry has moved to the adoption of SCM philosophy, without having benefited from earler philosophies in other industry sectors such as Just-in-time, TotalQuality Management, and Concurrent Engineering \{Khalfan et al. 2001). In other words, features from the above mentioned philosophies have become part of current practices of construction industry because of the adoption of SCM which Iay the foundation of integrated construction supply chain. One of the features of the integrated construction supply chain is that they are centrally coordinated and the relationship between firms is maintained for the duration of a specific project and beyond. These chains are not only directed towards the minimisation of transaction costs, but also towards enhancement and transfer of expertise between all the parties (Vrijhoef and Voordijk, 2003). This paper will review the literature related to the construction supply chain integration; efforts in the form of current reports; industrial practices in order to achieve supply chain integration within construction industry; and will also give a brief overview and initial findings of a project undertaken by the authors at the Scri Research Centre at University of Salford.

\section{A REVIEW OF SUPPLY CHAIN MANAGEMENT IN CONSTRUCTION}

In construction industry, increasing number of construction organisations have started showing a realisation towards the importance of SCM concept (Akintoye et al, 2000; Vrijhoef and Koskela, 2000; Dainty et al 2001a) however unlike retail and manufacturing sectors, construction industry has been slow and reluctant in employing the concept of SCM (Love, 2000). According to Ofori (2001) by using a SCM philosophy, various problems associated with the traditional practices in the construction industry can be resolved. These problems may arise due to the presence of win-lose arrangements; uncertainties encountered by 
various construction processes; lack of exchange of information and knowledge; increasing price competition due to the purchases of supplies from numerous suppliers; and the existence of environment of fear, dishonesty, and frustration (Asad et al., 2005).

Proverbs and Holt (2000) advocate the use of the SCM philosophy as a mean to effectively reduce the overall construction costs. They advocate early involvement of subcontractors and suppliers in a manner similar to the early involvement of the contractor during the procurement process. According to them this would give an opportunity to the concerned parties to offer their expertise which could result into potentialcost savings and can become a stepping stone in improving two way communication among the collaborating partners. On the other hand, Dainty et al. (2001b) have stressed on the need to facilitate inter-firm relationships, achieve mutual benefits, and build trust among key interfaces in the supply chain. According to them it is crucial to take away the deep-rooted barriers of traditional relationships and the adversarial culture, and instead, introduce a change management framework to facilitate the implementation of supply chain management at the operational level.

Tan (2001) on the other hand has identified the key drivers towards fully integrated supply chain. According to him, these drivers may include; changes in the corporate culture, trust and communication among all the parties involved, information/knowledge sharing, suppliers' evaluation for supplier development process, and sharing common goals of waste elimination and increased efficiency. Dainty et al. (2001a) have suggested changes which are required to make supply chain integration more effective. These changes include developing trust between parties; ensuring fair payments; early involvement with projects; educating the construction workforce; improving communication skills; knowing the operations of other type of organisations within construction supply chain; knowing the benefits of supply chain integration and partnering; understanding new contractual documents; client and main contractor organisations accepting that subcontractors can bring added values to the construction project delivery process; and willingness to share knowledge.
Barratt (2004) proposes a 'collaborative culture' for enhancing integration and improving collaboration among the supply chain partners within the construction industry. They are of the opinion that the collaborative culture is made up of number of elements including; external and internal trust; mutual pain and gain, information exchange in the supply chain, transparency and quality of information flow, communication and understanding, effective cross-functional activities and process alignment; joint decision making; use of measures to assess the performance of the whole supply chain, commit resources at the early stages of project development process, intra- and interorganisational support, corporate focus on SCM, demonstration of a business case for collaboration, and a notion that collaboration does not need to be based on technology. One of the ways to bring collaboration and integration within the industry is through aggregating the supply and demand, which would result into enhancing the collaboration among the construction firms. This will be discussed in details in the next section.

\section{RECENT REPORTS IN THE UK}

The Office of Government Commerce (OGC) works with the UK Government to improve procurement and project/programme management. They also work with suppliers to make the government marketplace more efficient and attractive to business. Another Government department, The Department of Trade and Industry (DTI) drives the UK Government's ambition of 'prosperity for all' by working to create the best environment for business success in the UK. They help people and companies become more productive by promoting enterprise, innovation and creativity. This section will give a brief overview on some of the recent reports published by the above mentioned organisations, which has already started impacting the integration within the construction supply chain, as these reports are now forming the shape of the naw publ;c procurement policies. The purpose of the OGC guide (2002) is look at the three areas of procurement:

- Analysing demand information both within a government organisation and across different organisation; 
- Taking decisions on whether to seek aggregated deals, i.e. to engage in collaborative deals between departments; and

- Taking decisions on whether to bundle good and services together into a single contract.

The report discusses both the aggregation or coordination of demand and the aggregation or consolidation of supply (see Figure 1).

Aggregating demand means:

- Analysing historical purchasing data to provide the management information necessary to assess purchasing practices and trends;

- Drawing together information on common or similar current or future requirements, either within an organisation and/or with other organisations; and

- Assessing the potential for collaborating with other business units within an organisation or with other organisations and agreeing to present these requirements in a coordinated way to the market.

Sometimes, instead of grouping together the information on common or similar requirement, we include diverse but related requirements then we refer to this as bundling.

\section{AGGREGATION OF SUPPLY:}

When the aggregated demand is presented in a consolidated way to the market, a single supplier or fewer suppliers may respond and contract with us. This is a likely market response to aggregated demand presented in a consolidated way to the market. Aggregation issues should be considered as early as possible in any project that involves procurement. The potential advantages of aggregation are:

- Better management information through aggregation of demand;

- Greater leverage;

- Lower prices through reduced production costs;

- Lower transaction costs;

- Better management of the market; and

- Better management of the supply chain.

- On the other hand, there are some potential drawbacks of aggregation:

- Need for highly skilled procurers and contract managers;

- Distorting the market and missing out on innovation; and

- Invisible supply chain.

The aggregation report also presents a checklist of questions to be considered in reaching decisions about aggregation. The basic aim of another report of the OGC, the Kelly Report (2003), was to advise OGC on what further steps can be taken in order to increase competition and encourage better long-term capacity planning in markets (including the construction industry), where the Government possesses significant purchasing power. 


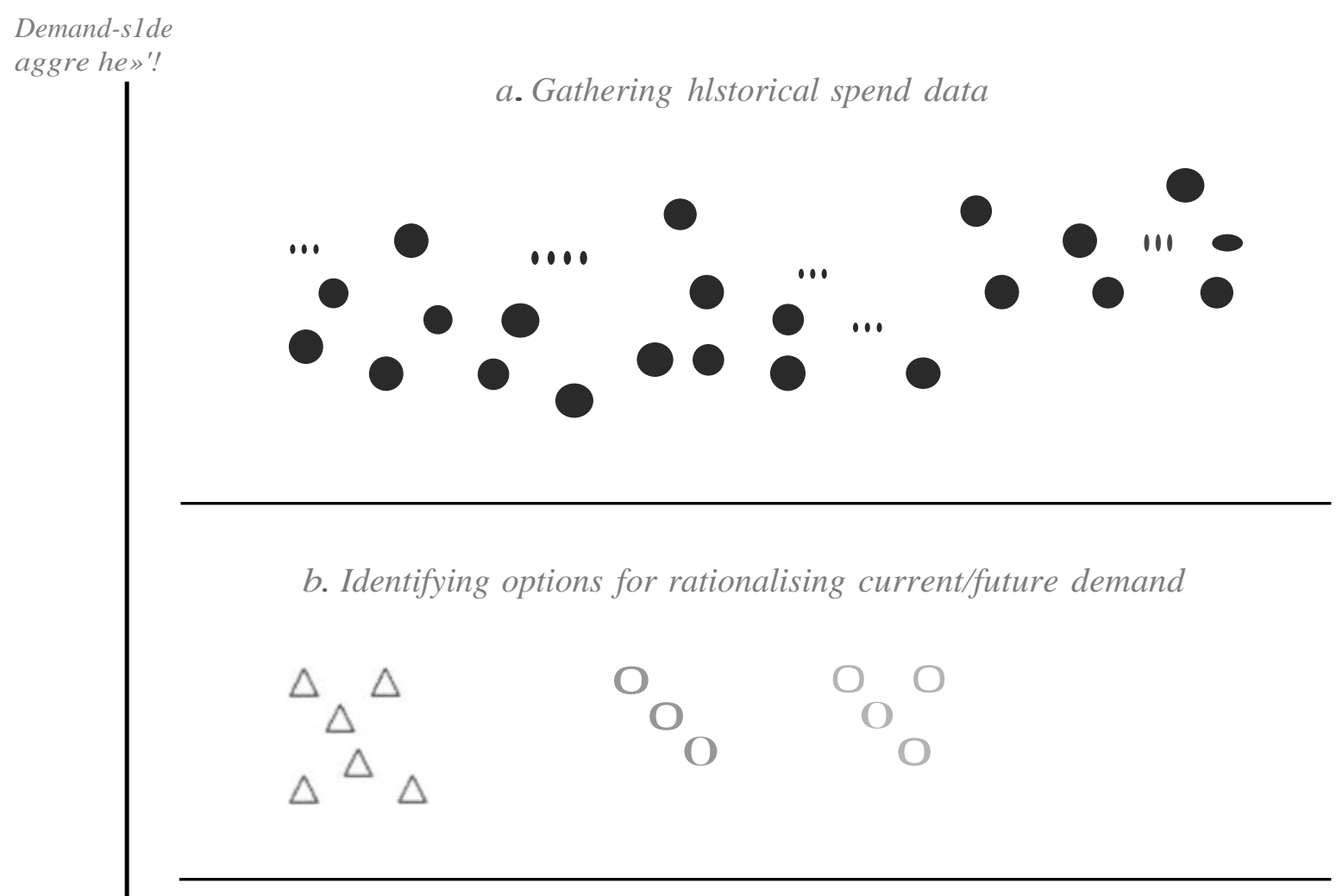

c. Deciding to consolidate reqwrements to present them to the market

Aggregation

ojsuppiy

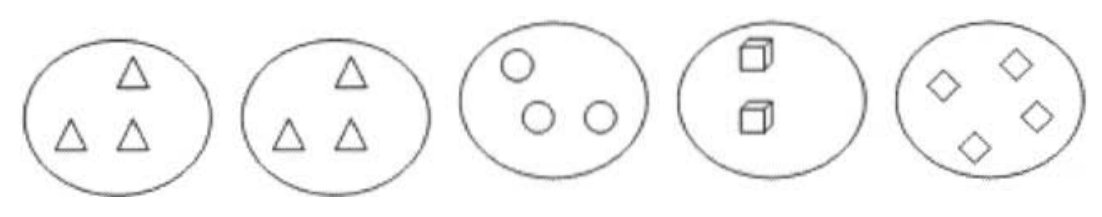

d. Market provides a response to the aggregated demand

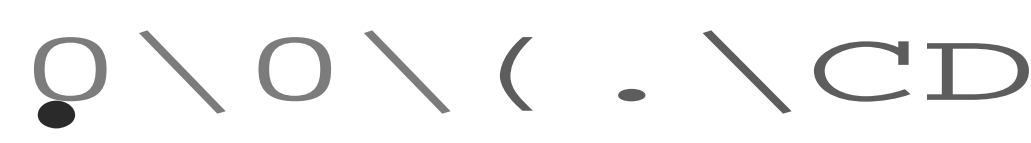

Figure 1: An illustration of the aggregation process (OGC Report, 2002)

The report suggests that all Government departments should work towards providing the information on their future needs (e.g. for a specific area, say construction), in order to correspond with industry lead times, engage early with key suppliers throughout the supply chain and take supplier's needs into account in their business planning. This will also result into a better understanding of the public sector's likely demands on the industry and the nature of the market to meet those demands. 
The Government, as a Client, needs to develop the markets in order to improve their capacity but on the other hand, needs to improve its own capability. Improvement within the procurement system is crucial. This may include development of a guideline on how to engage in early dialogue with suppliers while adhering to the principles of open competition and work on better ways of sharing information between departments about the performance of individual suppliers. This is also believed that if the public sector

(Government) and the industry work together and help each other, they both could bring about substantialimprovement within the construction sector.

\section{EXAMPLES}

In the North West of England, an initiative by the local government and the social housing landlords (RSLS) has resulted into FUSION 21 (http://www.fusion21.co.ukl). The initiative has adopted the whole idea of bundling the present and future demands of different client organisations and putting them forward into the market to get the best price from the subcontractors and suppliers in return of certainty of continuous workflow. The organisation is also involved in skill development of the local labour and the details can be found on the website provided above. Another project with the same region, called Elevate (http://www.elevateeastlancs.co.uk) is also trying to introduce the ideas and lessons learnt from FUSION 21. As discussed above, the bundling of demands by the local government and initiatives by central government departments have raised awareness and now more and more companies, especially SMEs are collaborating and offering their services as a package, as a supply in response to the demands. Prime contracting, a type of construction contract, is becoming popular among the local government because the prime contractor comes with the integrated supply chain to offer the supply of services and products in response to the demands of client organisations. Ministry of Defence (MoD) is the main player in getting benefits from prime contracting. Research and consultancy work is also being done with Manchester City Council by the authors, who are taking lead in the North West of the England to bundle their demands for educational facilities in different packages and in response they have awarded prime contracts to three contractors who have come forward to supply products and services in the integrated manner for primary schools.

\section{THE SUPPLY CHAIN INTEGRATION PROJECT}

As part of the investigation into drivers of supply chain integration, the authors are conducting a series of case studies as part of their research project with different companies including the public sector. FUSION 21 and Elevate, both organisations, are part of the case studies. These case studies are generating the propositions around the concepts, theories and policies presented earlier in the last section. Some of theories will be discussed in the later sections as well. The project is now intended to test both theory and policy implementation within the companies that influence supply chain integration and will also investigate the extent to which the above mentioned concepts are being implemented with the construction industry. The original aim of the research proposal is to determine if there are ways of integrating the supply chain that will ensure service and product quality whilst still supporting the government and client initiatives, aimed at increasing the competitiveness of the construction sector (Khalfan et al., 2004). Literature reviews has already been carried out and semi-structured interviews are being conducted as part of the project which will explore the changes that are occurring throughout the supply chain. The project has already looked at some of the concepts that are important within the supply and demand management context and affect the overall supply chain integration within the construction industry, which will be discussed in the next sections. This includes knowledge of suppliers' capacity; clients' role in demand aggregation; achieving demand and supply management through innovative procurement routes; etc.

When this paper is being written (end of May 2005), the researchers have identified the projects and companies represented on the steering committee based on the unit of analysis and selection criteria to conduct the in-depth and small case studies. At this stage, the findings from the first round of interviews are being analysed by using Soft System Methodology (SSM), which researchers are intending to use for the rest of the case studies as well. Figure 2 shows the transformation within the construction industry due to introduction of SCM. 
An integrated construction supply chain arrangement to enable supply chain participants to work in collaboration over a longer period in order to develop relationship based on trust and bring value for money for the construction clients.

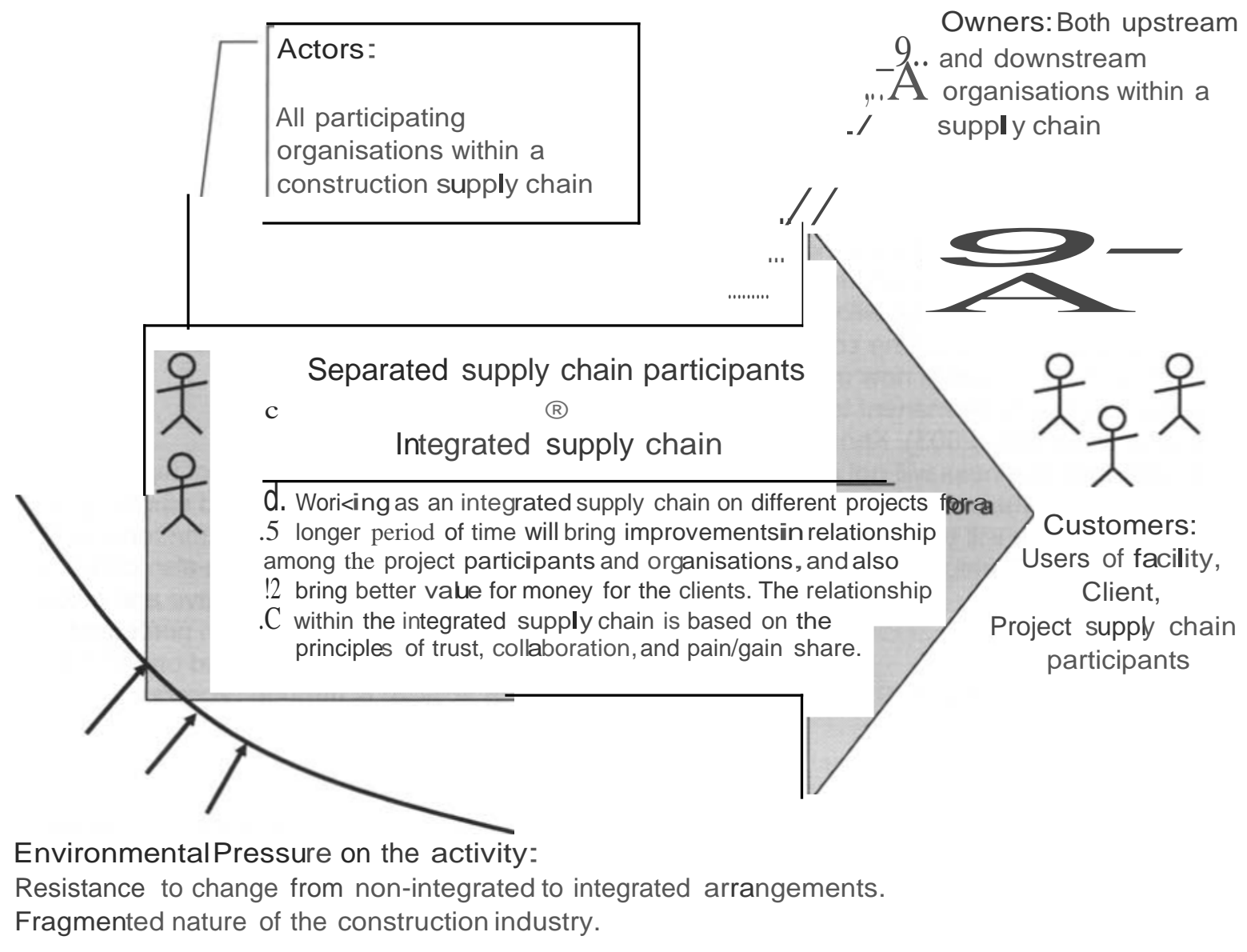

Figure 2: An example of the transformation to integrated supply chain within construction industry

\section{FRAGMENTATION}

The fragmentation issue within the construction industry came out cl early during the first phase of interviews. The problem is how to manage the fragmentation and also how to reduce that fragmentation. This is fact that we can not eliminate fragmentation! And in order to manage this fragmentation, we need some management mechanism, including concurrent engineering, lean thinking, supply chain philosophy, etc. Fragmentation is classified as the number of participants working on one project. If it is a complex project then there is likelihood that there would be more participants involved in that project, resulting in a more fragmented project.
The question arises; why there is a fragmentation? Since there are no barriers in place for people to enter into the construction business, therefore, there are many SMEs and one-man companies involved in the business, some with literally no skl at all! Secondly, all project participants coming from different backgrounds and have different goal s related to their current work on a specific project. Unless we have common understanding and common goals to achieve in a supply chain, it is difficult to manage everybody involved in the project supply chain. One of the solutions is to integrate all the participants at different levels, which could help in resolving this problem, i.e. by integrating them, by bringing common understanding at different levels within a supply chain. 
INTEGRATION OF SUPPLY CHAIN MEANS KNOWING THE SUPPLY CHAIN

It is very important for the each member or participant of an integrated supply chain to know first of all the whole process of the construction and secondly and the important thing is to know the business of the other participants/members of the supply chain. People come together as a team, and work for a number of years and then disperse; this trend is now out of fashion due to new procurement methods adopted by different companies within the construction industry as discussed earlier . It is now becoming necessary to know more about the people, personally and professionally, with whom we work within a team because the concept of construction project team is now moving from temporary to virtually permanent team (Vrijhoef and Voordijk, 2003). Knowing the people and their business will not only bring new culture within the industry but will also bring benefits which will be enjoyed by everybody within an integrated supply chain (Khalfan et al., 2005).

\section{CONSTRUCTION CLIENTS' ROLE AND POWER IN INTEGRATION}

Clients have played a central role in construction, and this has been studied for a long time (Cherns and Bryant, 1984), including with regards to supply chain integration (Khalfan and McDermott, 2005). Some authors have criticised and called for change in clients' procurement strategies and tendering procedures (Millett et al., 2001; Wong et al., 2000). It has been argued that clients have a critical role for integration of the supply chain because it is the client that makes the initial decision to procure construction works and the way in which procurement takes place (Briscoe et al., 2004). However the majority of clients within the construction industry are not in a position of dominance over the supply chain because of the nature of their ad-hoc construction profile combined with their limited understanding of the marketplace. Only the regular clients are in the better position to be able to leverage the supply chain effectively and implement integrated supply chain management concept successfully through introducing new procurement strategies such as partnering, strategic alliances etc. In addition to the type and position of clients within the construction sector they are in, various external factors are affecting clients' roles and power vis-a-vis their supply bases, including size of the suppliers market, global or local suppliers market, influence of regulations on clients (public or private), and market share of the client, e.g. large clients dominating other smaller clients in particular client markets, having major influence on suppliers, and thus the ability to exercise power on the supply chain, or even mobilise own integrated supply chain, e.g. through framework agreements with contractors, specialists, suppliers, architects, structural engineer etc.

\section{ACHIEVING EFFECTIVE INTEGRATION THROUGH PROCUREMENT}

Figure 3 shows the direct link of high degree of supply chain effectiveness and efficiency to the high degree of the integration among the supply chain participants. This also concludes that in order to get more effective and efficient performance from construction personnel, integrate them into a team. And one of the ways to achieve is through procurement.

The historical or traditional procurement process (see Figure 4) was the acceptable process in the construction industry for many decades. The process had made a specific culture within the construction industry relying on a mere lowest price focus and projectbased approaches contrbuting towards inefficiencies of the construction process.

More recently new procurement processes are being initiated aimed at more integrated organisation of processes. This can be considered as a "transitional process" (see Figure 5). This process includes two-stage selection procedures and partnering concepts.

A desirable next step is to move towards the "aspirational process" (see Figure 6), which is based on the whole concept of integration and collaborative working and shared objectives within a reconfigured and integrated supply chain. 


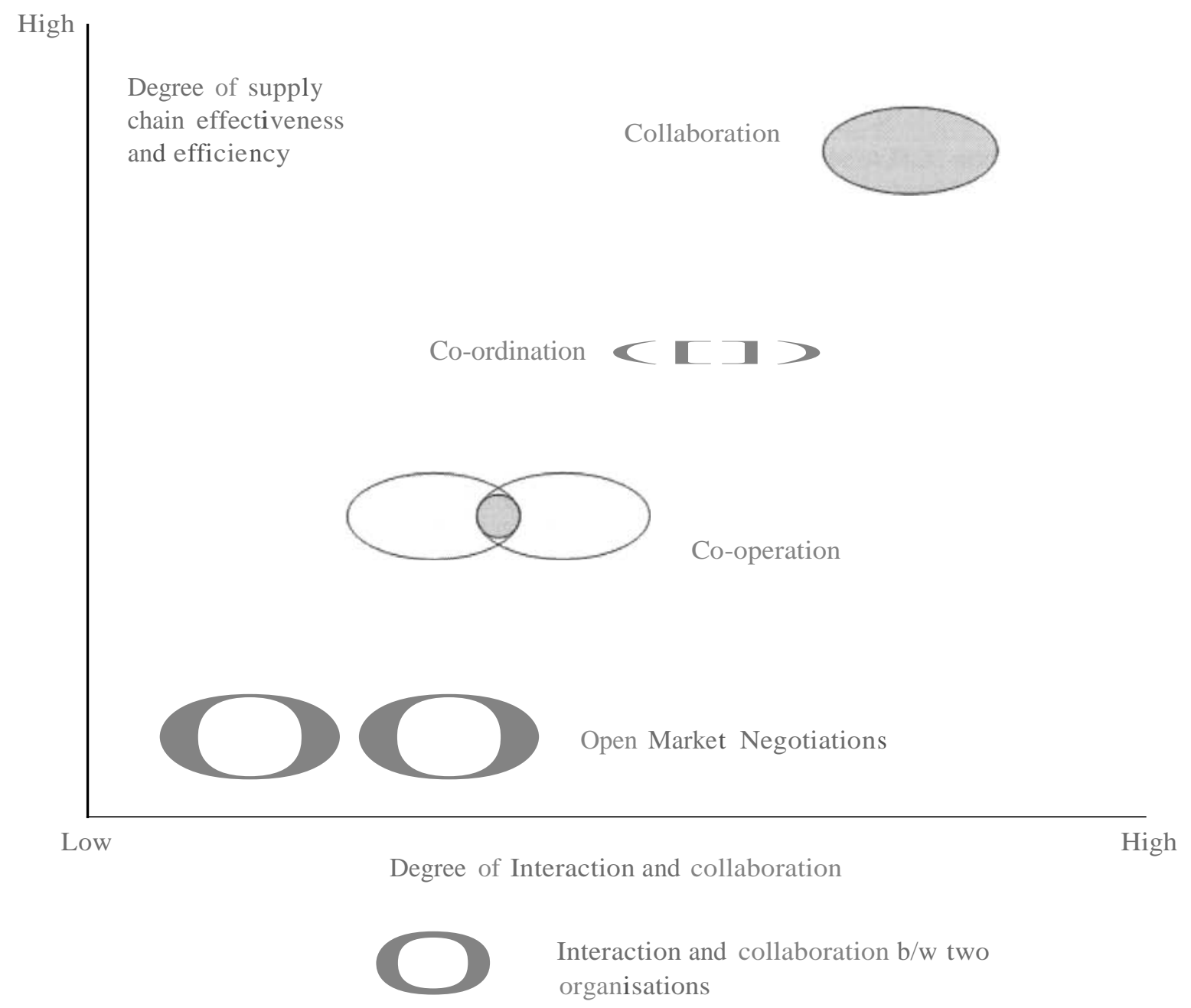

Figure 3: Move from traditionalopen market negotiation to collaboration (Khalfan et al., 2004)

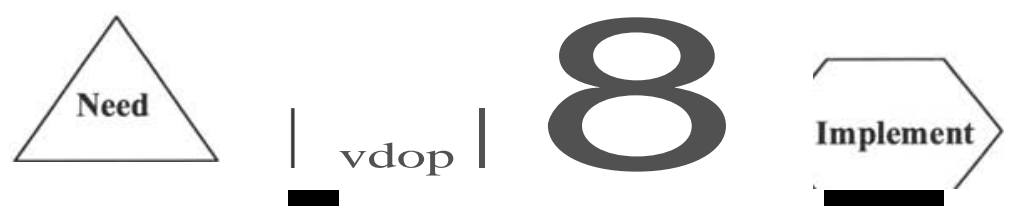

Figure 4: The Historic Procurement Process

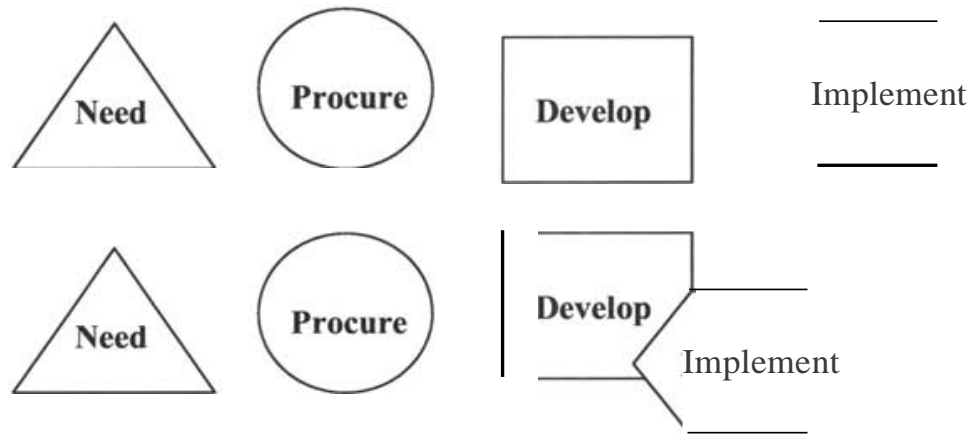

Figurer 5: The Transitional Process 


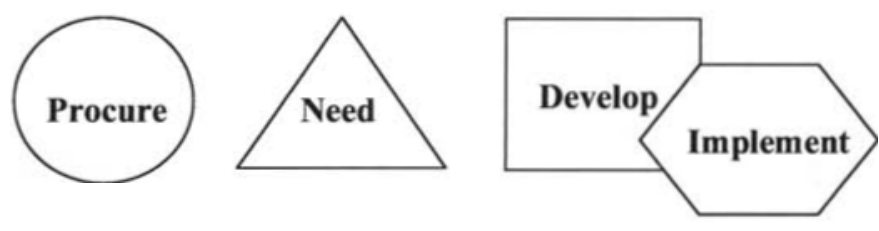

Figure 6: The Aspirational Process

Various examples of strategic thinking and longterm structured action by clients in terms of their procurement policies and methods have shown positive effects on value and efficiency levels of construction processes (Khalfan and McDermott, 2006).

\section{SUMMARY}

Integrated procurement approaches and supply and demand management are often associated with conditions of mutual dependency, integration, collaboration, goal sharing, and trust. This notion is largely reflecting what most previous authors have been arguing with regards to the above mentioned concept. This paper briefly described the concept of supply chain management and demand and supply management which are in the literature and are being practiced currently within the construction industry due to the publication of different reports. The paper also gave an update on the supply chain integration project, being carried out at the SCRI Research Centre. The impact of the discussed concepts is beginning to be felt by construction practitioners through the UK Government construction procurement policies and is being investigated by the authors.

The basic aim of conducting case studies as part of the research project is to observe an organisation working on a specific project and observe integration of the supply chain on that project. The prospective company is expected to give researchers access to one of their projects. On completi on of the case studies, planned for the research project, the authors are expected to be able to comment and describe the validity and application of the discussed concepts in more detail, and report on their successful implementation and changes experienced by different organisations involved in the process.

\section{REFERENCES}

Akintoye, A.; Mcintosh, G. and Fitzgerald, E. (2000), A survey of supply chain collaboration and management in the UK construction industry, European Journal of Purchasing and Supply Management , Vol. 6, 2000, pp. 159168.

Asad, S.; Khalfan, M. M. A. and McDermott, P. (2005), Managing Knowledge across the Construction Supply Chain, SCRI

Symposium in Salford, 12 - 13 April, pp. 2.25235.

Barratt, M. (2004), Understanding the meaning of collaboration in the supply chain, Supply Chain Management: An International Journal, Vol. 9, No. 1, pp. $30-42$.

Bertelsen, S. \{1997), Just-in-time logistics in the supply of building materials, in proceedings of $1^{51}$ international conference on Construction Industry Development: Building the Future Together, 9-11 December, Singapore.

Briscoe, G. H. ; Dainty, A. R. J. and Millett, S. (2001\}, Construction supply chain partnerships: skills, knowledge and attitudinal requirements, European Journal of Purchasing \& Supply Management, Vol.?, pp. 243-255.

Briscoe, G.H., Dainty, A.R.J., Millett, S.J., and Neale, R.H. (2004), Client-led strategies for construction supply chain improvement, Construction Management and Economics 22 (2\}, 193-201.

Cherns, A.B., and Bryant, D.T. \{1984), Studying the client's role in construction management, Construction Management and Economics 2, 177-184. 
Dainty, A. R. J.; Briscoe, G. H. and Millett, S. (2001a), Subcontractor perspective of supply chain alliances, Construction Management and Economics, Vol. 19, pp. 841-848.

Dainty, A. R. J.; Briscoe, G. H. and Millett, S. (2001b), New perspectives on construction supply chain integration, Supply Chain Management: An International Journal, Vol. 6, No. 4, pp. 163-173.

Khalfan, M. M.A.; Anumba, C. J.; Siemieniuch, C. E. \& Sinclair, M. A. (2001), Readiness Assessment of the Construction Supply Chain A Necessity for Concurrent Engineering in Construction, European Journal of Purchasing and Supply Management, Volume 7, Issue 2, pp. 141-153.

Khalfan, M. M. A., McDermott, P.; and Cooper, R. (2004), Integrating the supply chain within construction industry, Proceedings of $2 \mathrm{dh}$ ARCOM Conference, Heriot Watt University, 13 September, Vol. 2, pp. 897-904.

Khalfan, M.M.A., and McDermott, P. (2005). Clients" role towards the integrated supply chain within construction industry, in Proceedings of W92 Conference in Las Vegas, 8-10 February 2005, Vol. 2, pp. $529-537$.

Khalfan, M. M. A.; McDermott, P.; Tzortzopoulos, P. and Aouad, G. (2005), Achieving supply chain integration through knowing the supply chain participants, CIB W102 Conference on Information and Knowledge Management in a Global Economy, Lisbon, Portugal, 19 - 20 May 2005, pp. $279-288$.

Khalfan, M. M. A., and McDermott, P. (2006), Innovating for supply chain integration within construction, Journal of Construction Innovation, Vol. 6, pp.143 - 157.

London, K.; Kenley, R. and Agapiou, A. (1998), Theoretical supply chain network modellinin the building industry, in proceedings of $14^{1}$ Annual ARCOM Conference, University of Reading, 9 - 11 September, Vol. 2, pp. 369 379.
Love, P.E.D. (2000), Construction supply chains, European Journal of Purchasing and Supply Management, Vol6 No. 3-4, pp. 145-7.

Millett, S.J., Dainty, A.R.J., and Briscoe, G.H. (2001), Client procurement strategies:a crosssectoral analysis, In: Proceedings 17th Annual ARCOM Conference. 5-7 September 2001, Salford. University of Salford. 907-915.

O'Brien, W.; London, K. and Vrijhoef, R. (2002), Construction supply chain modelling: a research review and interdisciplinary research agenda, 1Oth Annual Conference of the International Group for Lean Construction, Gramado, Brazil, 6-8 August, pp. $129-148$.

Ofori, G. (2000), Greening the construction supply chain in Singapore, European Journal of Purchasing and Supply Management, Vol.6, 2000, pp. 195-206.

OGC Report (2002), Aggregation, OGC Report.

OGC Report (2003), Increasing competition and improving long-term capacity planning in the Government market place, OGC Report, Chancellor of the Exchequer, December.

Proverbs, D. G. and Holt, G. D. (2000), Reducing construction costs: European best practice supply chain implications, European Journal of Purchasing and Supply Management, Vol. 6, pp. $149-158$.

Saad, M.; Jones, M. and James, P. (2002), A review of the progress towards the adoption of supply chain management relationships in construction, European Journal of Purchasing and Supply Management, Vol. 8, 2002, pp. 173 183.

Tan, K. C. (2001), A framework of supply chain management literature, European Journal of Purchasing and Supply Management, Vol. 7, 2001' pp. $39-48$.

Vrijhoef, R. and Koskela, L. (2000), The four roles of supply chain management in construction, European Journal of Purchasing 
and Supply Management, Vol. 6, 2000, pp. 169178.

Vrijhoef, R. and Voordijk, H. (2003), 'Improving supply chain management in construction:what can be learned from the food and grocery sector?', CIB Joint International Symposium on Knowledge Construction, 22-24 October, Singapore.
Wong, C. H., Holt, G.D., and Cooper, P.A. (2000). Lowest price or value?: investigation of UK construction clients" tender selection process, Construction Management and Economics 18, 767-774. 